\title{
Chitohexaose protects against acetaminophen-induced hepatotoxicity in mice
}

\author{
PK Barman ${ }^{1}$, R Mukherjee ${ }^{1}$, BK Prusty ${ }^{1}$, S Suklabaidya ${ }^{2,3}$, S Senapati ${ }^{2}$ and B Ravindran, ${ }^{*}$
}

Acetaminophen (N-acetyl-para-aminophenol (APAP)) toxicity causes acute liver failure by inducing centrilobular hepatic damage as a consequence of mitochondrial oxidative stress. Sterile inflammation, triggered by hepatic damage, facilitates gut bacterial translocation leading to systemic inflammation; TLR4-mediated activation by LPS has been shown to have a critical role in APAPmediated hepatotoxicity. In this study, we demonstrate significant protection mediated by chitohexaose (Chtx) in mice challenged with a lethal dose of APAP (400 mg/kg b.w.). Decreased mortality by Chtx was associated with reduced hepatic damage, increased peritoneal migration of neutrophils, decreased mRNA expression of IL-1 $\beta$ as well as inhibition of inflammasome activation in liver. Further, an alternate mouse model of co-administration of a sublethal doses of APAP ( $200 \mathrm{mg} / \mathrm{kg} \mathrm{b.w.)} \mathrm{and} \mathrm{LPS} \mathrm{(5} \mathrm{mg/kg} \mathrm{b.w.)}$ operating synergistically and mediating complete mortality was developed. Overwhelming inflammation, characterized by increased inflammatory cytokines (TNF- $\alpha$, IL-1 $\beta$ and so on) in liver as well as in circulation and mortality was demonstrable in this model. Also, Chtx administration mediated significant reversal of mortality in APAP+LPS co-administered mice, which was associated with reduced IL-1 $\beta$ in liver and plasma cytokines in this model. In conclusion, Chtx being a small molecular weight linear carbohydrate offers promise for clinical management of liver failure associated with APAP overdose.

Cell Death and Disease (2016) 7, e2224; doi:10.1038/cddis.2016.131; published online 12 May 2016

Acetaminophen (N-acetyl-para-aminophenol (APAP)) toxicity remains the leading cause of acute liver failure globally, making it a major public health concern. ${ }^{1-4}$ APAP hepatotoxicity is initiated by the production of reactive intermediate $\mathrm{N}$-acetyl-p-benzoquinone imine, ${ }^{5}$ which under physiological conditions is detoxified by preferential binding to glutathione. ${ }^{6,7}$ However, under APAP overdose, excessive induction of $\mathrm{N}$-acetyl-p-benzoquinone imine results in rapid depletion of glutathione that leads to the formation of protein adducts with $\mathrm{N}$-acetyl-p-benzoquinone imine causing mitochondrial oxidative stress and hepatocellular necrosis. ${ }^{8}$ The hepatic damage causes release of endogenous dangerassociated molecular patterns (DAMPs), leading to localized sterile inflammation ${ }^{9,10}$ and substantial accumulation of activated neutrophils ${ }^{11}$ and macrophages ${ }^{12}$ in liver. Sterile inflammation combined with gut bacterial translocation has been reported to trigger further activation of the innate immune system by pathogen-associated molecular patterns (PAMPs) through signaling by toll-like receptors. ${ }^{13-16}$ Thus, overwhelming systemic inflammation along with hepatic damage causes acute liver failure to mortality.

Experimental studies with TLR $4^{14-16}$ and mice deficient for lipopolysaccharide-binding protein $^{17}$ have unequivocally established the role played by TLR4 and LPS in mediating APAP-induced toxicity. Successful demonstration of reduced APAP toxicity, using synthetic TLR4 antagonists ${ }^{14,18}$ and inhibitor of lipopolysaccharide-binding protein, ${ }^{19}$ have further strengthened the TLR4-LPS nexus in APAP-induced liver dysfunction. Currently, the only available antidote for APAP toxicity is N-acetylcysteine (NAC), a ROS scavenger, which functions by replenishing glutathione and thus blocking hepatic damage. ${ }^{7,20-22}$ However, NAC therapy has been found to be effective only when patients are treated at very early stages of acute overdose; delayed and prolonged administration results in enhanced toxicity and impaired liver regeneration. ${ }^{23-25}$

We had earlier demonstrated that chitohexose (Chtx), a low molecular weight chito-oligosaccharide, binds to TLR4 and activates macrophages by the alternate pathway (as opposed to the classical inflammatory pathway) and consequently inhibits LPS-mediated inflammation both in vitro and in vivo. ${ }^{26}$ We had shown that Chtx protects mice from experimental endotoxemia both prophylactically and therapeutically. A recent report demonstrating that impairment of macrophage switching from classically activated/pro-inflammatory phenotype to alternatively activated/wound repair phenotype reduces APAP toxicity, emphasizing the critical role played by alternatively activated macrophages in recovery of APAPinduced liver damage. ${ }^{27}$ This attracted our attention because we had shown that Chtx induces alternate activation of macrophages through its binding to TLR4. In this report, we demonstrate that Chtx protects mice from APAP-induced toxicity and mortality by reducing centrilobular hepatic damage and decreased inflammation in liver, which was further associated with increased neutrophil migration in peritoneum and inhibition of inflammasome pathway in liver.

\footnotetext{
${ }^{1}$ Infectious Disease Biology Group, Institute of Life Sciences, Bhubaneswar, India; ${ }^{2}$ Translational Research Group, Institute of Life Sciences, Bhubaneswar, India and ${ }^{3}$ Manipal University, Manipal, India

*Corresponding author: B Ravindran, Infectious Disease Biology, Institute of Life Sciences, Bhubaneswar 751023, India; Tel: +916742301900; Fax: +916742300728. E-mail: balaravi@ils.res.in or ravindran8@gmail.com

Abbreviations: APAP, acetaminophen; DAMPs, danger-associated molecular pattern; TLRs, toll-like receptors; Chtx, Chitohexaose; LPS, lipopolysaccharide; TNF- $\alpha$, tumor necrosis factor- $\alpha$; IL, interleukin; NAC, N-acetylcysteine

Received 11.1.16; revised 05.4.16; accepted 07.4.16; Edited by A Stephanou
} 

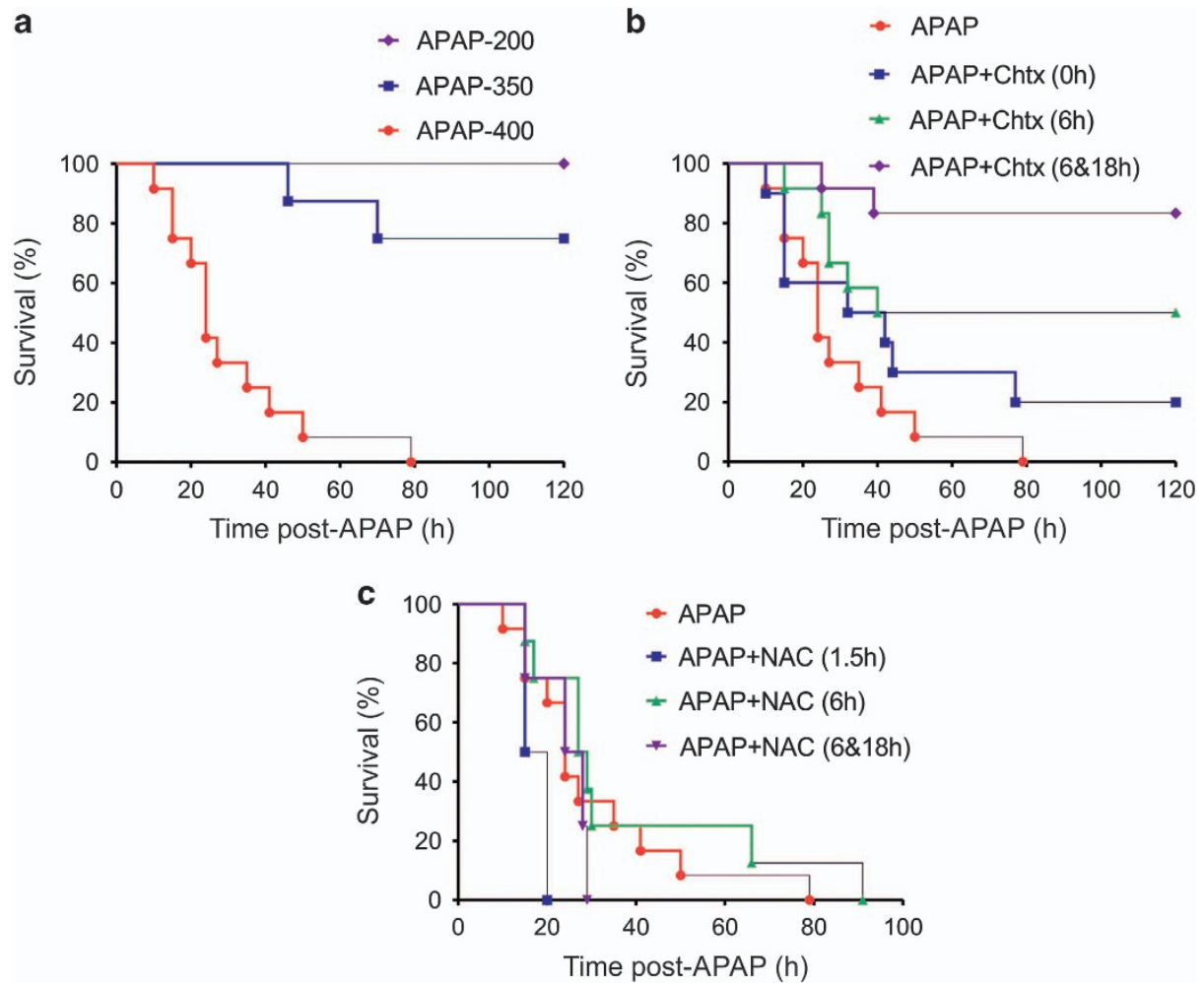

Figure 1 Chtx protects mice against APAP-induced mortality. (a) Titrated doses of APAP reveal 100\% mortality only in mice receiving $400 \mathrm{mg} / \mathrm{kg}$ b.w. (APAP-200: $n=7$; APAP-350: $n=8$; APAP-400: $n=12$ ). (b) A single dose of Chtx administered at 0 or $6 \mathrm{~h}$ post APAP resulted in survival of $20 \%$ and $50 \%$ of mice, respectively, while two doses of Chtx injected at 6 and $18 \mathrm{~h}$ post APAP led to $83 \%$ survival of mice against LD100 of APAP (APAP: $n=12$, APAP+Chtx ( $0 \mathrm{~h}): n=10, \operatorname{APAP}+\mathrm{Chtx}(6 \mathrm{~h}): n=12, \operatorname{APAP}+\mathrm{Chtx}(6 \mathrm{and}$ $18 \mathrm{~h}$ ): $n=12$ ). (c) Administration of a single dose of NAC at $1.5 \mathrm{~h}$ or $6 \mathrm{~h}$ or two doses at 6 and $18 \mathrm{~h}$ failed to protect mice against LD100 of APAP (APAP: $n=12$, APAP+NAC $(1.5 \mathrm{~h}): n=4$, APAP+NAC (6h): $n=8$, APAP+NAC (6 and 18h): $n=4)$

Besides, we describe that low doses of LPS and APAP act synergistically, and mutually potentiate local (liver) and systemic inflammation leading to mortality in mice, and neutralization of Chtx reverses the toxicity mutually induced by APAP and LPS in this model also.

\section{Results}

Chtx reduces APAP-induced mortality. Overnight starved male C57BL/6 mice were treated with titrated doses of APAP (200, 350 and $400 \mathrm{mg} / \mathrm{kg}$ b.w. i.p.) and followed for 5 days to score mortality. Despite showing typical signs and symptoms of APAP toxicity, mice injected with $200 \mathrm{mg} / \mathrm{kg}$ b.w. fully recovered, while $25 \%$ and $100 \%$ of animals in the 350 and $400 \mathrm{mg} / \mathrm{kg}$ b.w treatment groups died of APAP toxicity, respectively (Figure 1a). Liver necrosis, plasma inflammatory cytokines, IL-1- $\beta$ transcript and cleaved caspase-1 in liver were significantly more in mice injected with the $400 \mathrm{mg}$ dose in comparison with animals injected with $200 \mathrm{mg}$ (Supplementary Figure 1). A dose of $400 \mathrm{mg} / \mathrm{kg}$ b.w. was selected for further experimentation. Mice were randomized in four treatment groups: group 1, APAP only; group 2, APAP and a single dose of Chtx injected simultaneously; group 3, APAP followed by a single dose of Chtx at $6 \mathrm{~h}$ post APAP and group 4, APAP followed by two doses of Chtx at 6 and $18 \mathrm{~h}$ post APAP for survival study. The results are shown in Figure $1 \mathrm{~b}-20 \%$ and $50 \%$ of animals survived APAP-induced toxicity in group 2 and group 3, respectively, while none of the control mice (group 1) survived APAP challenge. Further, administration of two doses of Chtx at 6 and $18 \mathrm{~h}$ following APAP treatment significantly reduced mortality with a survival rate of $83 \%$ (group 4). NAC, on the other hand, at the dose of $300 \mathrm{mg} / \mathrm{kg}$ b.w. used in this study failed to protect mice from APAP-induced mortality, suggesting that Chtx is superior to NAC for treating APAP-induced liver toxicity (Figure 1c).

Chtx ameliorates APAP-induced liver damage and inflammation. To test whether improved survival observed in Chtx treatment of APAP hepatotoxicity correlated with the degree of liver injury, histological evaluation of paraffin-sectioned livers collected at $12 \mathrm{~h}$ post administration of APAP was performed. Chtx administration at $6 \mathrm{~h}$ post APAP injection remarkably decreased centrilobular hepatic necrosis in response to APAP challenge as shown by H\&E staining (APAP, $50.14 \pm 0.63 \%$ versus APAP + Chtx, $30.07 \pm 5.6 \%$ area of damage; ${ }^{\star} P=0.0242$ at $\times 100$ magnification; Figures $2 a$ and $b$, upper panels). This was further correlated with the degree of DNA fragmentation; the number of terminal deoxynucleotidyl transferase-mediated dUTP nick-end labeling (TUNEL)-positive cells in necrotic area of liver in response to APAP was significantly decreased by treatment with Chtx (APAP, $77.73 \pm 8.5$ versus APAP+Chtx, $22.67 \pm 5.86$ number 
a Liver histology-12hrs post-APAP

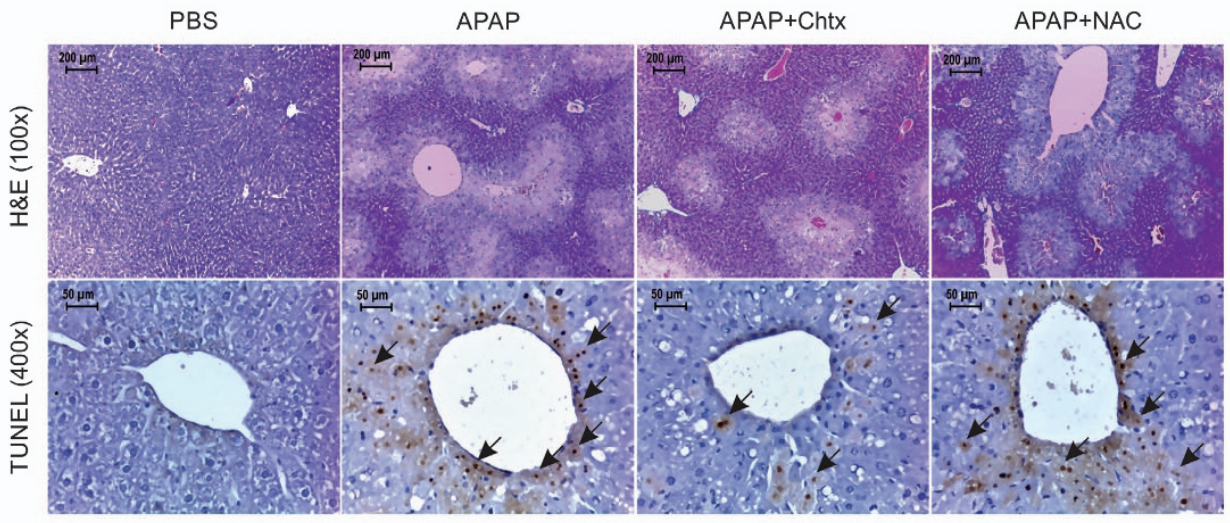

b

Cell death

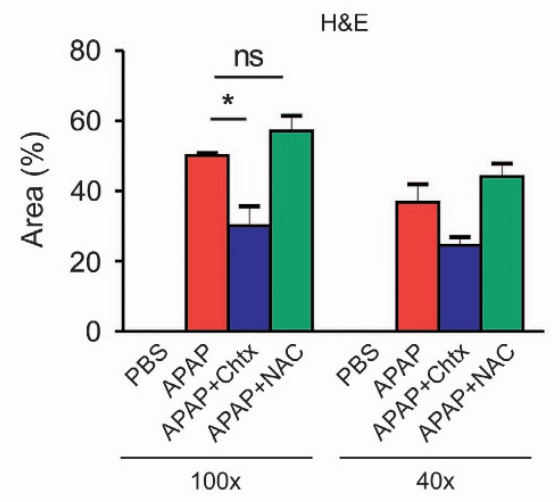

c

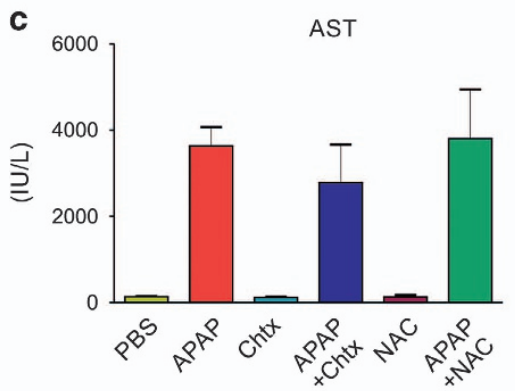

e

Pro-IL-1 $\beta$

TUNEL assay
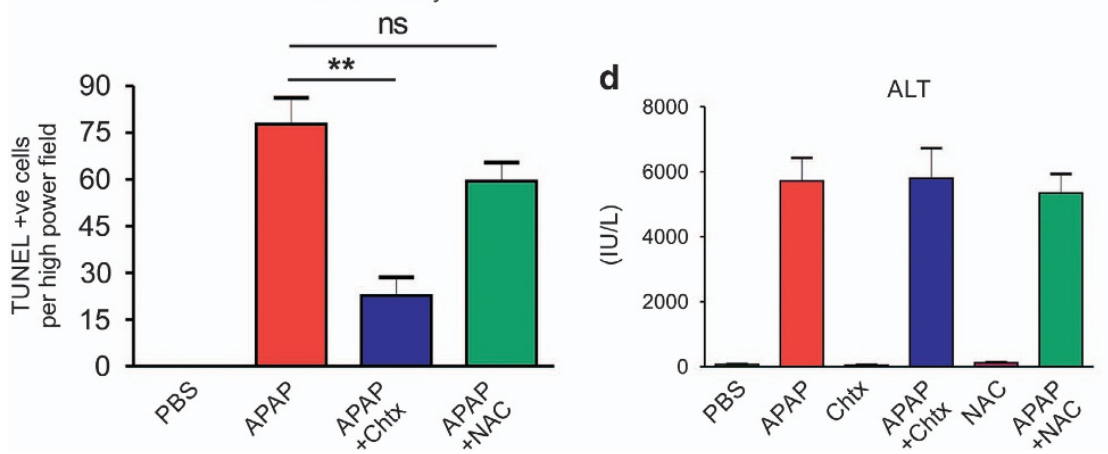

f

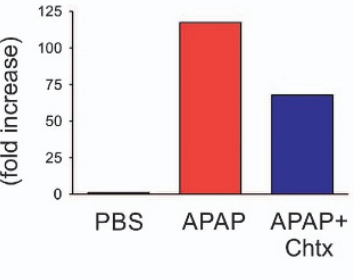

Arginase-1

(Liver)

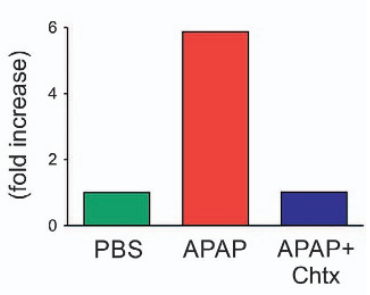

Figure 2 Chtx reduces hepatic necrosis and inflammation in mice challenged with APAP. (a and $\mathbf{b}$ ) H\&E staining and TUNEL assay: mice were injected with a single dose of Chtx or NAC at 6 or $1.5 \mathrm{~h}$ post APAP (LD100), respectively. At $12 \mathrm{~h}$ post APAP challenge, APAP-induced centrilobular hepatic damage was reduced upon Chtx treatment as indicated by the decreased area of necrosis and DNA fragmentation. The hepatic damage was not altered by treatment with NAC $\left(n=3\right.$ mice per group, $\left.{ }^{*} P<0.05,{ }^{* *} P<0.01\right)$. Necrotic area scored at $\times 100$ and $\times 40$ magnifications are shown. Arrow heads indicate TUNEL-positive cells. (c and d) Plasma AST and ALT levels at $12 \mathrm{~h}$ post APAP were comparable in mice injected with APAP or APAP+Chtx or APAP+NAC (PBS: $n=5$, APAP: $n=3$, APAP+Chtx: $n=3$, APAP+NAC: $n=5$ ). (e and f) Q-PCR analysis for IL- $1 \beta$ and Arg1 expression in liver of mice injected with APAP or APAP+Chtx at $12 \mathrm{~h}$ post APAP challenge. Data were normalized with $\beta$-actin (PBS: $n=5$, APAP: $n=6$, APAP+Chtx: $n=6$, $\mathrm{IL}-1 \beta 2^{-\Delta \mathrm{cT}}$ values; PBS $-740.4 \pm 225$, APAP $-26.52 \pm 10.99$, APAP $+C h t x-52.53 \pm 15.53, P=0.201$ (APAP versus APAP+Chtx), Arg $12^{-\Delta c T}$ values; PBS 140.5 \pm 101 , APAP $840 \pm 606.4$, APAP + Chtx 112.7 $\pm 113.1, P=0.265$ (APAP versus APAP+Chtx)). Results were expressed as mean \pm S.E.M.

of TUNEL-positive cells per high-power field, ${ }^{* *} P=0.006$; Figures $2 a$ and $b$, lower panels). Despite the difference in hepatic damage as shown by histology, plasma levels of liver enzymes (alanine amino transferase and aspartate amino transferase) were comparable in both the groups at $12 \mathrm{~h}$ post APAP injection (Figures $2 \mathrm{c}$ and $\mathrm{d}$ ). Correlating to the mortality, NAC did not alter hepatic damge as revealed by
H\&E staining, TUNEL assay and plasma levels of aspartate amino transferase/alanine amino transferase (Figures 2a-d). Further, to establish an association of Chtx-mediated reduction of APAP-induced hepatic damage to liver inflammation, we quantified pro-IL-1 $\beta$ transcripts in liver at $12 \mathrm{~h}$ post APAP administration. In comparison with the 117-fold increase in pro-IL-1 $\beta$ expression in APAP-challenged mouse livers 
a

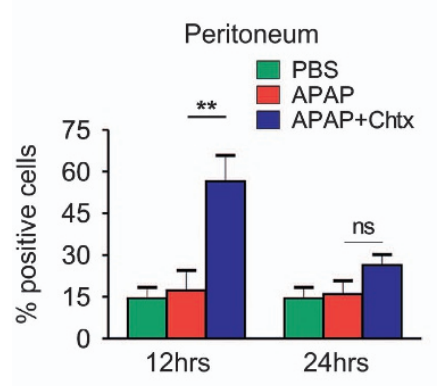

c

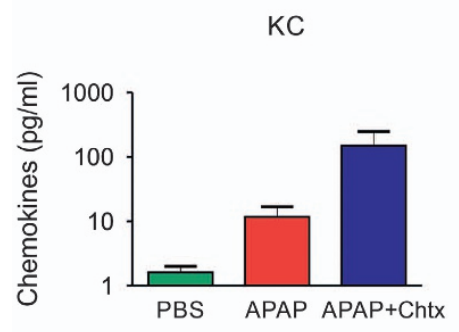

Neutrophils

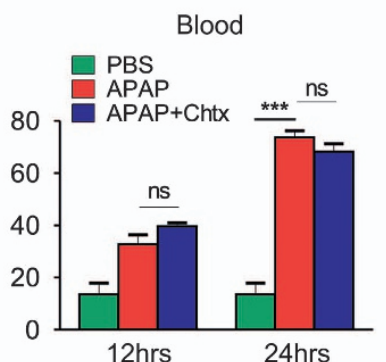

b

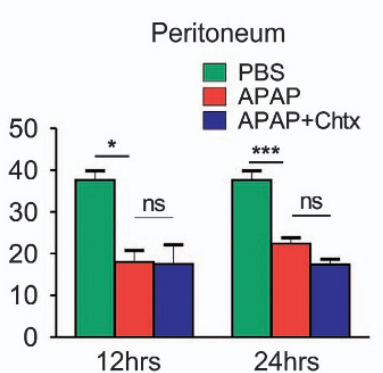

Monocytes

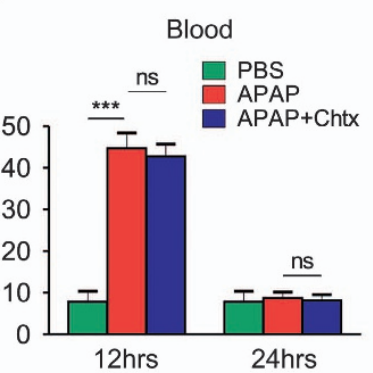

Peritoneal lavage-24hrs

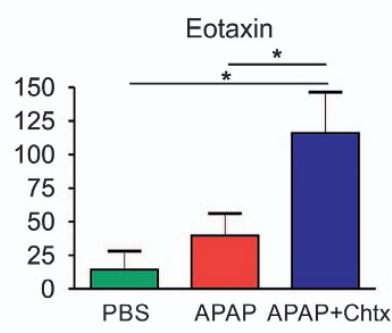

MCP-1

MIP-1a
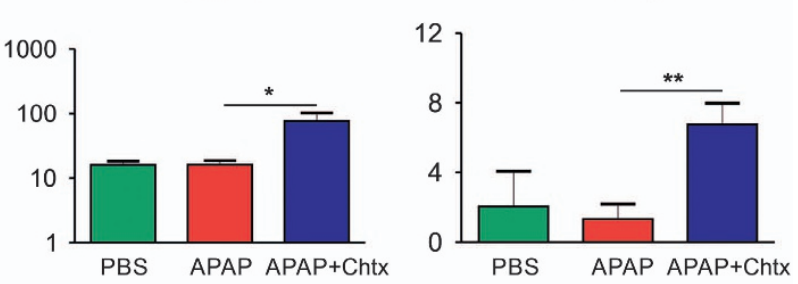

d
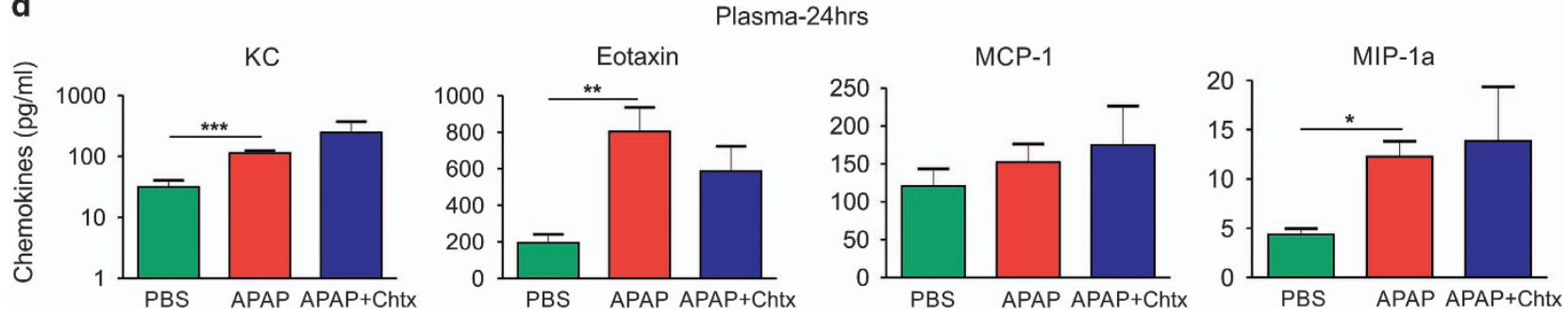

Figure 3 Chtx induces neutrophil migration and chemokine secretion in peritoneum of mice. (a and $\mathbf{b}$ ) Mice were injected with PBS, APAP alone or APAP followed by a single dose of Chtx at $6 \mathrm{~h}$ post APAP or two doses of Chtx at 6 and $18 \mathrm{~h}$ post APAP. Monocytes (CD14+Ly6G - ) and neutrophils (CD14-Ly6G+) from peritoneum and blood at 12 or $24 \mathrm{~h}$ post APAP treatment were analyzed by flow cytometry. (PBS: $n=4$, APAP: $n=6$, APAP+Chtx: $n=6,{ }^{\star *} P<0.01$ ). (c and d) After $24 \mathrm{~h}$ of treatment as mentioned above, chemokines in peritoneal exudates and plasma were measured by multiplex bioassay. KC, Eotaxin, MCP-1 and MIP-1a were upregulated in peritoneum of mice treated with APAP + Chtx, whereas their levels were comparable in plasma between APAP- and APAP+Chtx-treated groups (PBS: $n=4$, APAP: $n=7$, APAP+Chtx: $n=7,{ }^{*} P<0.05,{ }^{* *} P<0.01$, $\left.{ }^{* * *} P<0.001\right)$. Results were expressed as mean \pm S.E.M.

with respect to vehicle control, Chtx treatment resulted in only 67 -fold increase in IL-1 $\beta$ message, revealing significant amelioration of APAP-induced inflammation in liver by treatment with Chtx (Figure 2e).

Arginase-1 (Arg1) is predominantly present in liver and initiates a catalytic reaction leading to the conversion of arginine to proline, an essential component of collagen formation during wound healing. As a consequence, plasma level of $A r g 1$ is increased during liver injury, making it a liver injury-specific biomarker with more sensitivity than other standard parameters. ${ }^{28,29}$ The ability of Chtx in modulating the effect of APAP-induced expression of liver-specific Arg1 was studied. As expected, APAP upregulated Arg1 transcripts in liver and Chtx decreased this upregulated expression to basal level (Figure 2f). This observation positively correlated with our findings on reduced liver damage and mortality in Chtx-treated group of mice. However, liver arginase activity was decreased in mice treated with APAP at $12 \mathrm{~h}$ post treatment and came back to basal level at $24 \mathrm{~h}$. Besides, although a single dose of Chtx following APAP showed liver arginase activity similar to APAP-exposure alone at $12 \mathrm{~h}$ post
APAP, two doses of Chtx maintained reduced arginase activity at $24 \mathrm{~h}$ post APAP treatment (Supplementary Figure 1F).

Migration of neutrophils and level of chemokines are increased in peritoneum in the presence of Chtx. Given the fact that neutrophils and monocytes/macrophages have a crucial role in inducing inflammation and wound repair during injury, ${ }^{11,12,30,31}$ we scored these immune cells in both peritoneum and circulation at 12 and $24 \mathrm{~h}$ post APAP treatment by flow cytometry. No significant change was observed in Ly6G+ neutrophil percentage in peritoneum of mice challenged with APAP, while mice injected with APAP and Chtx induced significant migration of neutrophils in the peritoneum at $12 \mathrm{~h}$ post APAP injection $\left({ }^{\star \star} P<0.01\right.$, Figure $3 a$, left). The percentage of circulating neutrophils, on the other hand, increased at $12 \mathrm{~h}$ in mice treated with APAP with or without Chtx and reached to significantly higher levels at $24 \mathrm{~h}$ post treatment $\left({ }^{\star \star \star} P<0.001\right.$; Figure $3 \mathrm{a}$, right). Mice injected with APAP showed significant decrease in monocytes (Ly6G-CD14+) in peritoneum at $12 \mathrm{~h}$ post injection $\left({ }^{\star} P<0.05\right)$, which persisted till $24 \mathrm{~h}\left({ }^{\star \star \star} P<0.001\right)$ and 

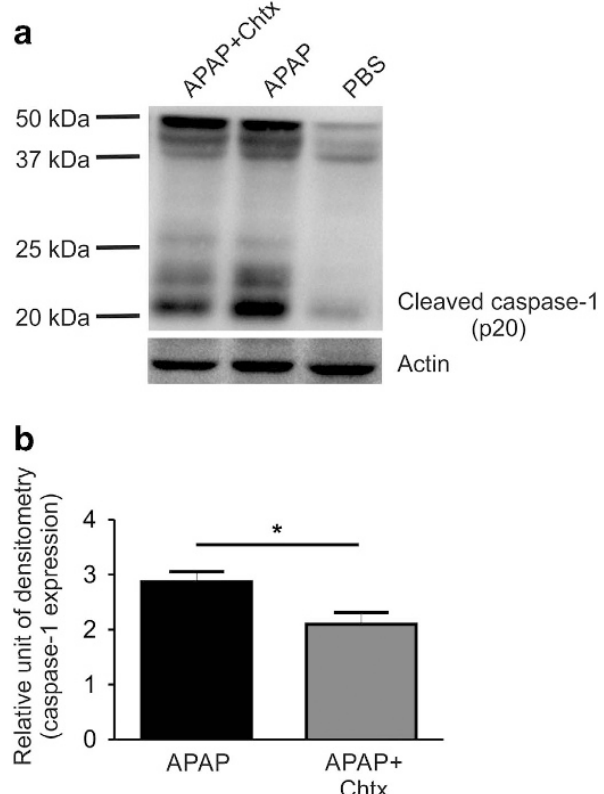

Figure 4 APAP-mediated activation of caspase-1 is reduced by Chtx. (a and $\mathbf{b}$ ) Mice were injected with PBS, APAP alone or APAP followed by two doses of Chtx at 6 and $18 \mathrm{~h}$ post APAP. At $24 \mathrm{~h}$ post APAP, caspase-1 activation in liver was examined by scoring cleaved caspase- 1 by western blotting $\left(n=3\right.$ mice per group, $\left.{ }^{*} P<0.05\right)$. Actin was used as the loading control. Results were expressed as mean \pm S.E.M.

Chtx treatment did not alter this decrease (Figure $3 b$, left). On the contrary, at $12 \mathrm{~h}$ post treatment, percentage of circulating monocytes were significantly increased $\left({ }^{* * *} P<0.001\right)$ in mice in both treatment groups and returned back to basal levels at $24 \mathrm{~h}$ (Figure 3b, right).

Quantification of KC, eotaxin, MCP-1 and MIP-1a in peritoneal lavage and plasma of mice at $24 \mathrm{~h}$ post treatment with APAP was undertaken with a view to study the influence of Chtx on APAP-mediated regulation of chemokine secretion. Chtx administration in APAP-treated mice significantly elevated peritoneal levels of the chemokines, revealing development of increased chemokine gradient in peritoneum in response to Chtx treatment (Figure 3c). Assessment of plasma chemokines revealed a significant increase in the levels of KC, eotaxin and MIP-1a by APAP. This increase in plasma levels were also observed in mice treated with $\mathrm{APAP}+\mathrm{Chtx}$ and there was no quantitative difference between these two treatment groups (Figure 3d). Similarly, levels of plasma inflammatory cytokines, namely, TNF- $a$, IL-1 $\beta$, IL-4, IL-5, IL-6 and IL-12p70 were also comparable in mice treated with APAP and APAP+Chtx (Supplementary Figure 2).

Chtx blocks APAP-mediated activation of inflammasome pathway. NLRP (NLR family, pyrin domain-containing) inflammasome, a multi-protein complex containing a member of the NLRP family, an adapter protein ASC and pro-caspase1 , is activated in response to DAMPs, released by tissue damage. The function of this complex is to convert inactive pro-caspase- 1 into active caspase-1, which in turn cleaves pro-IL-1 $\beta$ and pro-IL-18 into their active forms that finally trigger the inflammatory cascade. ${ }^{32,33}$ Absence of any of the components of inflammasome complex has been shown to result in reduced APAP hepatotoxicity. ${ }^{13}$ Further, a recent study has demonstrated that benzyl alcohol protects against APAP-mediated liver damage partly through blocking the cleavage of pro-caspase- $1 .{ }^{34}$ The possibility of Chtx blocking APAP-induced activation of inflammasome pathway was tested by studying cleaved caspase-1 in liver extracts. Consistent with earlier findings by other investigators, a marked increase in cleaved caspase-1 was observed in liver of mice upon APAP treatment as shown by western blotting and this elevated cleaved caspase- 1 was significantly decreased by Chtx treatment suggesting that Chtx significantly blocks APAP-induced activation of inflammasome pathway $\left({ }^{\star} P<0.05\right.$; Figures $4 a$ and $\left.b\right)$.

LPS enhances susceptibility of mice towards APAPinduced mortality. The observation that LPS pre-exposure intensifies sensitivity to APAP hepatotoxicity in mice provides a direct evidence for the critical role played by LPS in APAP-induced liver failure. ${ }^{35}$ Further, resistance of lipopolysaccharide-binding protein KO mice to APAPmediated liver injury and inhibition of APAP toxicity by lipopolysaccharide-binding protein inhibitory peptides demonstrated that LPS-mediated activation of the innate immune system is essential for APAP-induced liver failure. ${ }^{17,19}$ We reasoned that exogenous administration of a low dose of LPS and non-lethal dose of APAP could lead to synergistic potentiation of toxicity and disease progression. This was tested by co-administration of APAP $(200 \mathrm{mg} / \mathrm{kg}$ b.w.) and LPS (5 mg/kg b.w.) in mice. At this dose, neither APAP nor LPS caused mortality of mice ( $100 \%$ survival) while co-administration of the two resulted in $100 \%$ mortality (Figure 5a). Histological evaluation of liver sections showed no significant potentiation of APAP-induced liver necrosis by LPS administration, which was further reflected in plasma levels of aspartate amino transferase and alanine amino transferase, suggesting that LPS does not significantly increase induction of liver necrosis by low doses of APAP (Figures 5b-d). However, LPS increased both local (liver) and systemic inflammation when treated along with APAP as discussed below. On the basis of these observations, we conclude that LPS contributed by microbiota in mice are largely responsible for the observed inflammation and mortality in APAP-induced toxicity. This was experimentally tested in APAP-induced liver failure by scoring the mortality of mice in which the gut microbiota was depleted by prolonged antibiotic treatment. The results demonstrated significant protection of gut microbiota-depleted mice against APAP as compared with antibiotic untreated mice (Figure 5e).

APAP and LPS mutually enhance liver inflammation and activate inflammasome pathway in mice. To test the status of inflammation in liver due to the synergistic effect of APAP and LPS, liver mRNA expression of inflammatory cytokines and TLRs were quantified at $12 \mathrm{~h}$ post treatment. There was no significant increase in pro-IL- $1 \beta$ and TNF- $a$ transcripts in livers of mice individually treated with APAP and LPS, while co-administration of APAP and LPS resulted in log 
a
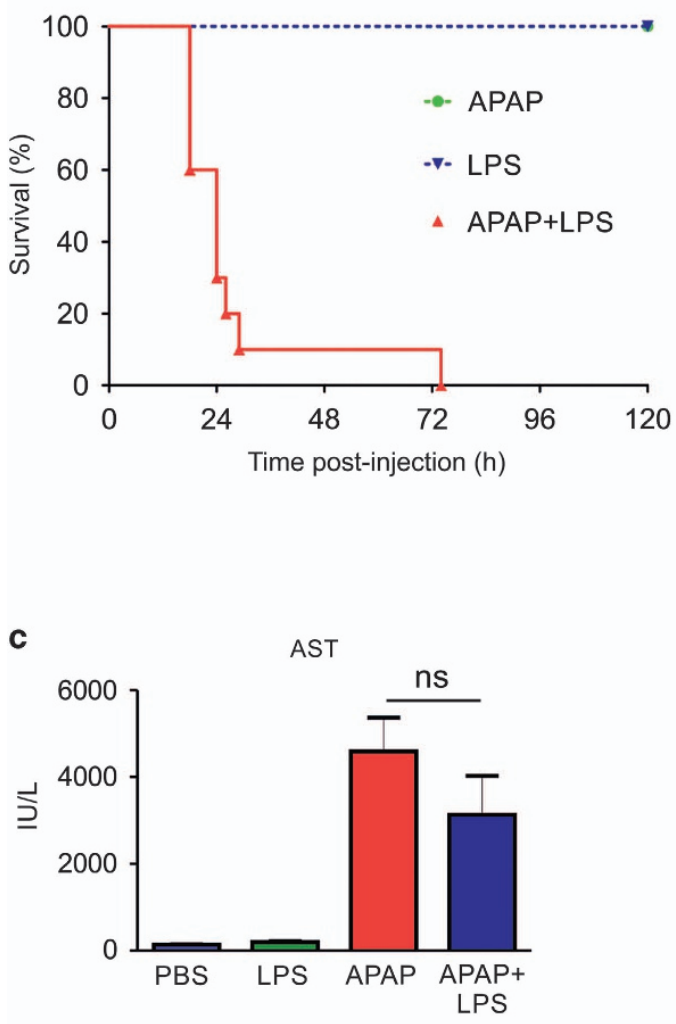

d

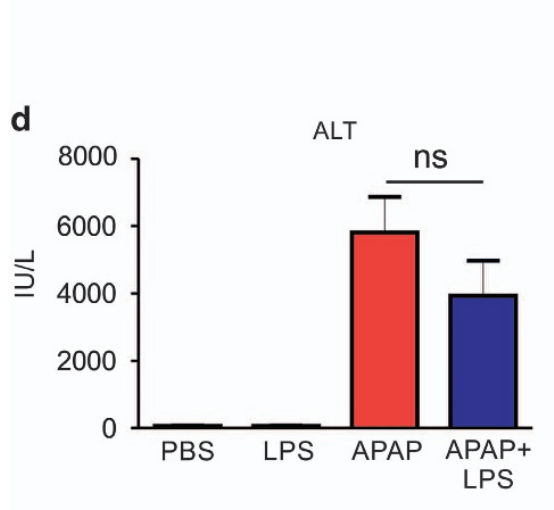

b

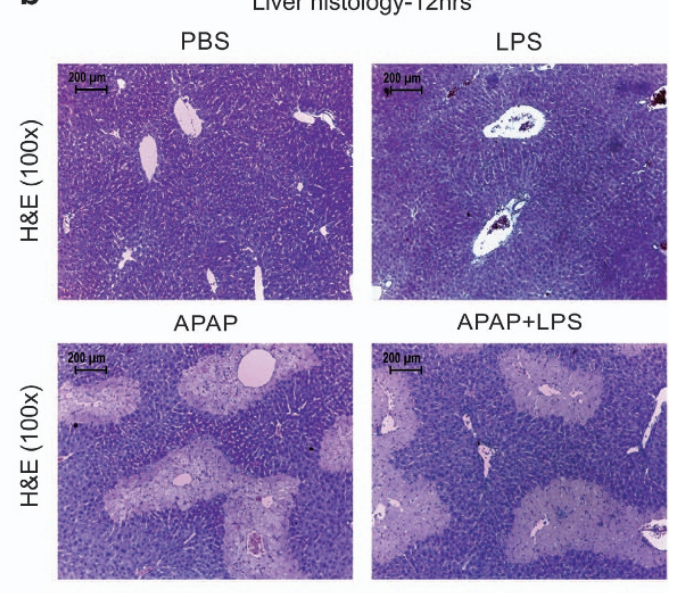

H\&E

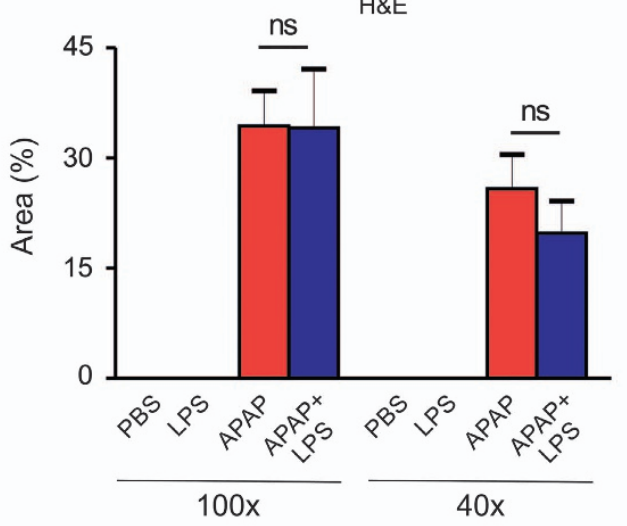

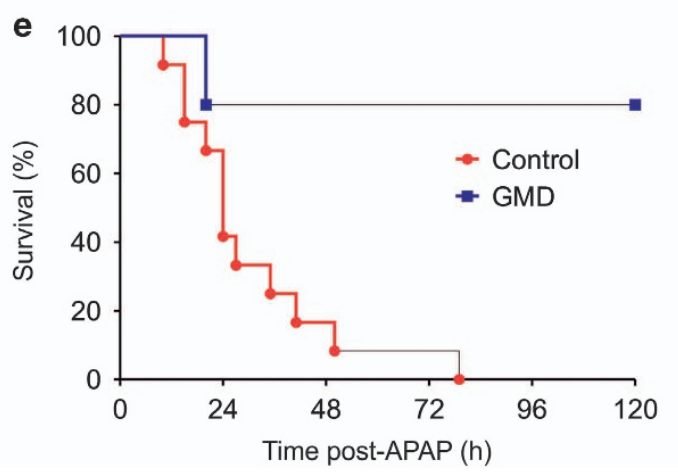

Figure 5 Non-lethal doses of APAP and LPS mutually induce mortality in mice. (a) Kaplan-Meier plot showing survival/mortality of mice, treated with APAP (200 mg/kg b.w.) alone, LPS ( $5 \mathrm{mg} / \mathrm{kg}$ b.w.) alone or APAP (200 mg/kg b.w.) and LPS ( $5 \mathrm{mg} / \mathrm{kg}$ b.w.) together (APAP: $n=6$, LPS: $n=10$, APAP+LPS: $n=10)$. (b) H\&E staining of liver biopsy ( $\times 100$ magnification) from mice $12 \mathrm{~h}$ after treatment with PBS, APAP, LPS and APAP+LPS showing comparable liver necrosis between APAP and APAP+LPS treatment groups. Necrotic area scored at $\times 100$ and $\times 40$ magnifications are shown. (c and d) Plasma AST/ALT were comparable between APAP- and APAP+LPS-treated mice at $12 \mathrm{~h}$ post treatment (PBS: $n=6$, APAP: $n=6$, LPS: $n=6$, APAP+LPS: $n=7$ ). Results were expressed as mean \pm S.E.M. (e) Survival/mortality of gut microbiota-depleted (GMD) and age-matched control C57BL/6 mice, treated with APAP (400 mg/kg b.w.) (GMD: $n=5$, Control: $n=12$ )

order increase in message for pro-IL-1 $\beta$ and TNF- $a$ (Figures $6 a$ and b). Similarly, expression of TLR2 (significantly) and TLR4 (non-significantly) increased in livers of mice injected with APAP and LPS together as compared with animals injected only with LPS or APAP (Figures $6 \mathrm{c}$ and d). Next, we examined whether APAP and LPS mutually potentiate the activation of inflammasome pathway. Nonlethal doses of APAP and LPS were unable to activate the inflammasome pathway as determined by the absence of cleaved caspase-1 in liver extracts, while co-administration of mice with APAP and LPS revealed marked increase in cleaved caspase-1, demonstrating synergistic activation of inflammasome pathway by APAP and LPS (Figure 6e).

APAP and LPS mutually potentiate systemic inflammation in mice. Increased inflammation in liver of mice coadministered with APAP and LPS was associated with 
a
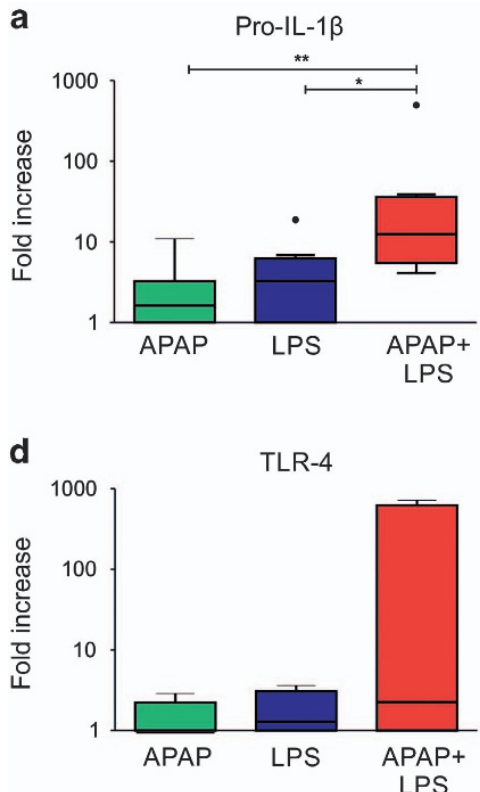

b

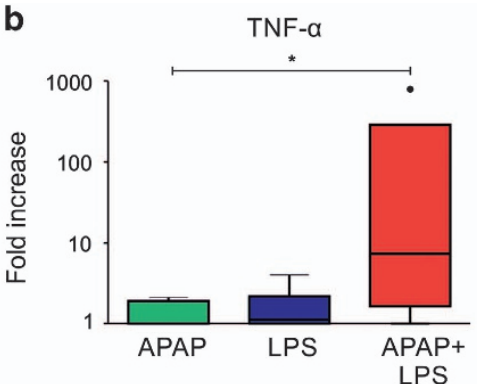

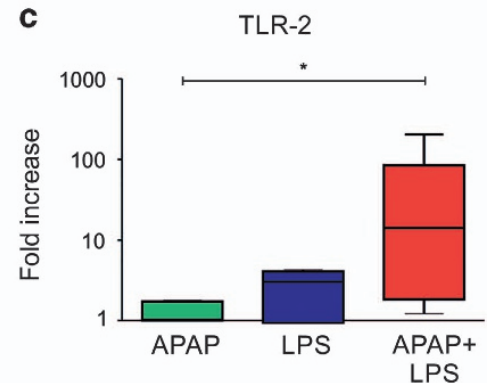

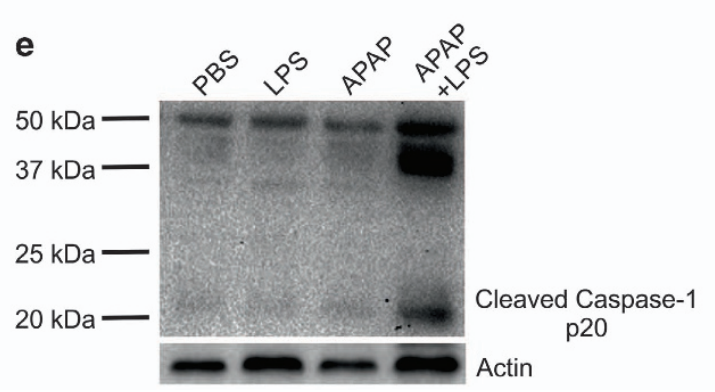

Figure 6 APAP and LPS mutually potentiate liver inflammation and activate caspase-1. (a-d) mRNA expression of pro-IL-1 $\beta$, TNF- $\alpha$, TLR2 and TLR4 in liver of mice treated with APAP, LPS and APAP+LPS measured by qPCR at $12 \mathrm{~h}$ post treatment. Data were presented as fold change with respect to PBS controls $\left(n=6-8\right.$ mice per group, ${ }^{*} P<0.05$, ${ }^{* *} P<0.01$ ). Results were expressed as mean \pm S.E.M. (e) Western blot shows presence of cleaved caspase- 1 in livers of mice at $12 \mathrm{~h}$ post treatment with APAP and LPS together. Actin was used as the loading control

systemic inflammation as shown by elevated levels of plasma mediators, particularly inflammatory cytokines. Analysis by multiplex cytokine array revealed that except IL-6, there was no significant change in other cytokines in plasma of mice treated only with APAP, whereas only LPS treatment significantly increased plasma IL-1 $\beta$, IL-6, MCP-1 and G-CSF levels in comparison with vehicle controls at $12 \mathrm{~h}$ post treatment. Further, co-administration of APAP and LPS significantly augmented the levels of IL-1 $\beta$, IL-6, IL-17, TNF- $\alpha$ and MCP-1 in comparison with treatments only with APAP or LPS, indicating synergism between APAP-mediated hepatic injury and LPS-mediated innate immune activation. Unexpectedly, G-CSF level was significantly elevated in plasma of mice treated with only LPS and it decreased significantly upon treatment with both APAP and LPS as compared with only LPS (Figure 7).

Chtx reduces mortality, liver injury and inflammation induced by treatment with APAP and LPS. The synergistic model of co-administration of APAP and LPS in which exacerbated local (liver) as well systemic inflammation and mortality was observed was used to test the efficacy of Chtx as a therapeutic agent. Chtx was administered in mice along with APAP and LPS and mortality was scored. Data revealed $50 \%$ reversal of APAP+LPS-induced mortality upon simultaneous treatment with Chtx. Decreased mortality was further associated with plasma levels of liver enzymes (Figures $8 \mathrm{a}$ and $\mathrm{c}$ ). Area of damage and pro-IL-1 $\beta$ transcripts in liver of mice given a combined dose of APAP, LPS and Chtx were found to be decreased (non-significantly) as compared with APAP+LPS-treated ones, whereas no difference was found in liver TNF-a expression between these two groups of mice (Figures 8b-e). Plasma cytokine read-outs showed that Chtx marginally reduced elevated levels of IL-1 $\beta, \mathrm{IL}-6, \mathrm{IL}-17$ and MCP-1 in response to APAP+LPS, without affecting TNF- $a$. On the other hand, plasma G-CSF content, which was reduced in mice combinedly treated with APAP+LPS, was significantly increased by Chtx (Figure 8f).

\section{Discussion}

The present study highlights the critical role of bacterial endotoxin LPS and microbiota in mediating APAP-induced hepatotoxicity and it also demonstrates that a carbohydrate Chtx, an LPS antagonist, induces protection against APAPinduced liver failure in mice. The observations of this investigation further reveal that the deleterious effect of APAP can be amplified by augmented inflammation and activation of inflammasome pathway by exogenous administration of LPS. These findings offer credence to the notion that APAP essentially leads to release of DAMPs by necrosis of liver cells and that further inflammation and mortality are essentially mediated by endogenous LPS from microbiota owing to a leaky gut. ${ }^{36-38}$ This study also demonstrates that blockade of LPS-mediated activation by a small molecular weight carbohydrate Chtx, which activates macrophages by alternate pathway through $\mathrm{TLR}_{4},{ }^{26}$ abrogates APAP toxicity in mice. The protection against APAP toxicity by Chtx appears to be mediated primarily by blocking the inflammasome activation pathway as shown by decreased cleaved caspase-1 in liver and also partly by reducing hepatic damage and liver tissue inflammation.

Although APAP toxicity is predominantly attributed to overdose of the drug, there are notable instances of APAP poisoning in individuals who were on therapeutic dosing. ${ }^{39}$ Growing evidence suggests the indispensible role of 

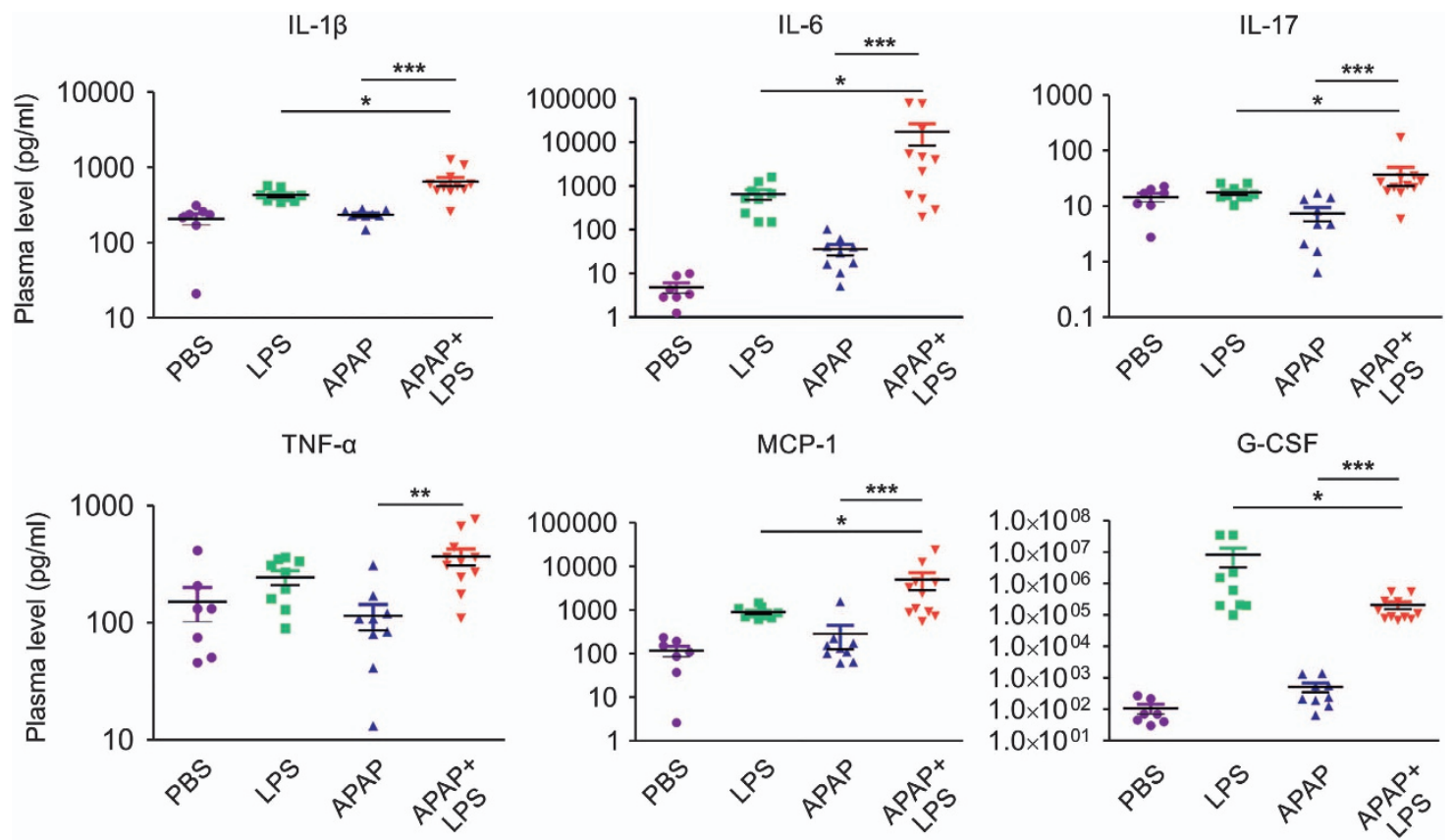

Figure 7 APAP and LPS mutually potentiate systemic inflammation - multiplex analysis for plasma cytokines. Mice were treated with PBS, LPS, APAP or APAP+LPS and at $12 \mathrm{~h}$ post treatment. Plasma cytokines were measured by multiplex bioassay. Plasma IL-1 $\beta$, IL-6, IL-17, TNF- $\alpha$ and MCP-1 were upregulated only in mice treated with both APAP and LPS but not with APAP or LPS alone at $12 \mathrm{~h}$ post treatment. G-CSF was downregulated in mice treated with APAP+LPS as compared with only LPS (PBS: $n=7, \mathrm{LPS}: n=9$, APAP: $n=9$, APAP+LPS: $\left.n=11,{ }^{\star} P<0.05,{ }^{* \star} P<0.01,{ }^{* \star *} P<0.001\right)$. Results were expressed as mean \pm S.E.M.

endogenous LPS and pre-existing inflammation in hepatotoxicity, mediated by xenobiotic agents. ${ }^{36-38}$ The finding that LPS priming renders mice more vulnerable to APAP toxicity while LPS tolerization lead to hypo-toxicity to APAP further corroborates the critical role of endogenous LPS in APAP-mediated liver dysfunction. ${ }^{35,40}$ In this context, our earlier observation that Chtx blocks LPS-mediated inflammation and endotoxemia in mice ${ }^{26}$ suggested that Chtx could potentially block APAP toxicity also, because LPS is needed for mediating such toxicity. We demonstrate that Chtx administration significantly reduces APAP-induced mortality in mice and protective effect is enhanced when Chtx is administered at later time points or by increasing the number of doses. These observations indicate that Chtx is predominantly effective in curing APAP-induced hepatotoxicity when applied at progressive and later stages of liver injury, making it superior to NAC for management of APAP-induced acute liver damage. The probable underlying mechanism behind Chtxmediated protection against lethal APAP dose was found to be inhibition of inflammasome pathway and partly by reduced hepatic damage as shown by histology and Arg1 and liver inflammation as shown by decreased IL- $1 \beta$. Hepatocellular necrosis, inflammation, both local (as shown by liver IL- $\beta$ transcripts) and systemic (as shown by plasma cytokines), and inflammasome activation correlate with mortality in mice by lethal versus non-lethal dose of APAP (Supplementary Figure 1). It is thus not surprising that Chtx-mediated protection of APAP toxicity results in significant decrease of liver damage, IL-1 $\beta$ expression and cleavage of caspase- 1 in liver.
The role of specific chemokines and certain immune cell subsets in liver injury, inflammation and repair are well known. ${ }^{11,12,41,42}$ Increased chemokine secretion post injury has been shown to trigger infiltration of neutrophils, macrophages and NKT cells in the damaged area. In the present study, we found a significant increase in plasma chemokines after lethal APAP challenge and this increase was not significantly altered by co-treatment with Chtx. Interestingly, Chtx treatment in APAP-administered mice enhanced chemokine density and displayed increased influx of neutrophils in the peritoneum. The significance of peritoneal infiltration of neutrophil and improved survival of mice against APAP is currently not clear.

Although mice models of APAP toxicity have been widely used in the past, in this study, an additional lethal model of APAP toxicity was developed, in which co-administration of non-lethal doses of APAP and LPS induced $100 \%$ lethality due to synergy between a PAMP such as LPS and DAMPs generated by APAP. This model of mortality demonstrated that it could be used in studies to investigate the intrinsic role of PAMPs in liver damage. Augmented inflammation, tissuespecific (increased pro-IL- $1 \beta$ and TNF- $\alpha$ expression in liver) as well as systemic (increased plasma IL- $\beta$, IL-6, IL-17 and MCP-1 levels) were responsible for the observed mortality in this model (Figures 6 and 7). Further, secretion of an antiinflammatory cytokine, such as G-CSF that gets elevated after LPS challenge as a compensatory mechanism, ${ }^{43,44}$ was impaired in APAP-LPS model of toxicity developed in this study. We propose that increased plasma G-CSF is a natural anti-inflammatory mechanism to counter-balance excessive inflammation by LPS. However, in the presence of 
a
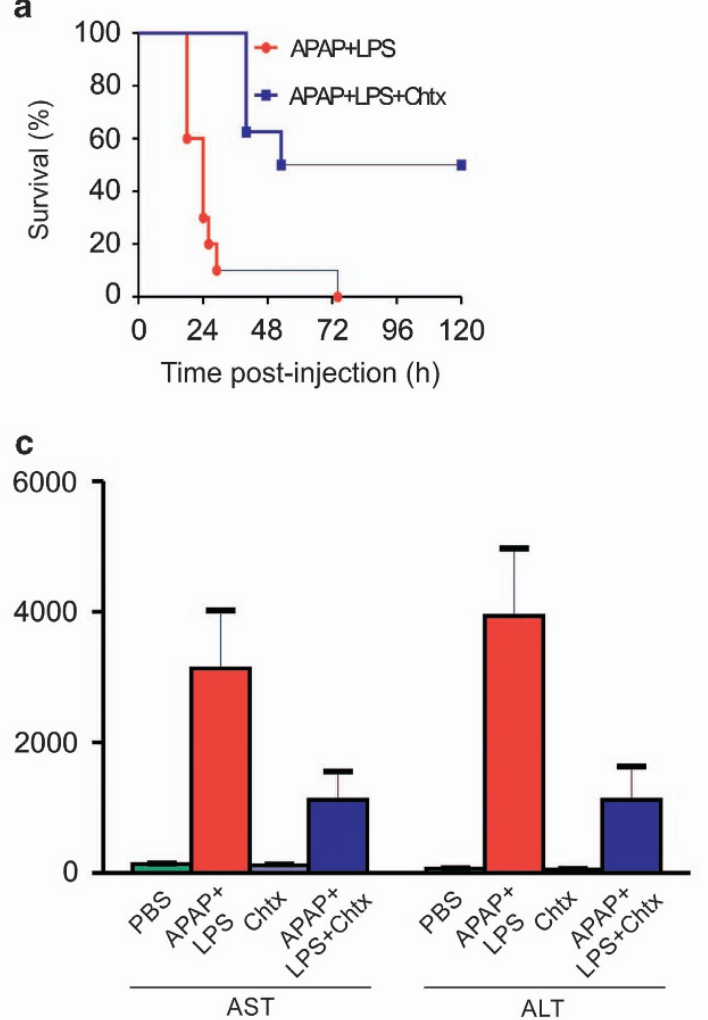

b
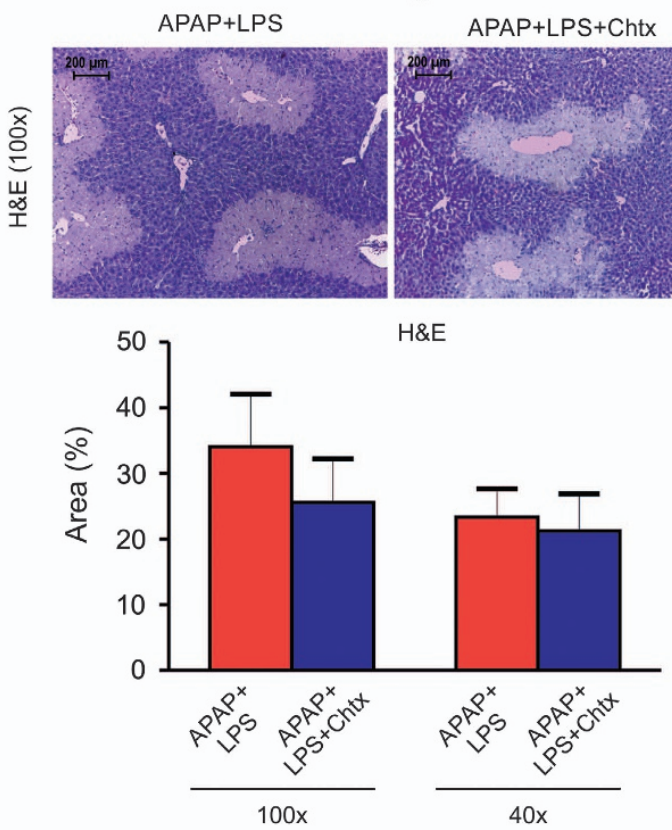
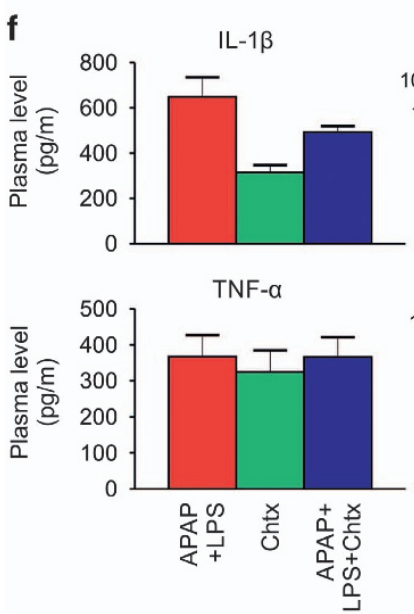

IL-6

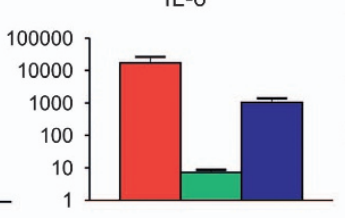

MCP-1

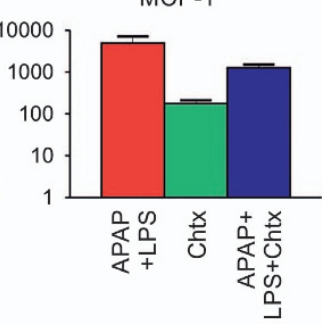

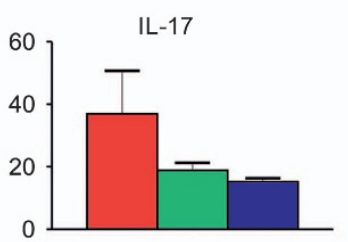

d

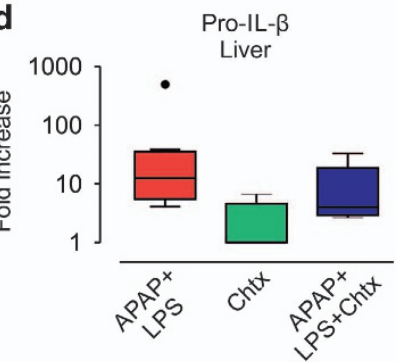

G-CSF

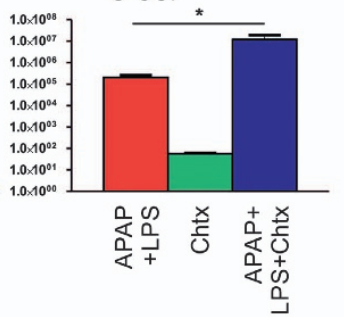

APAP+LPS+Chtx

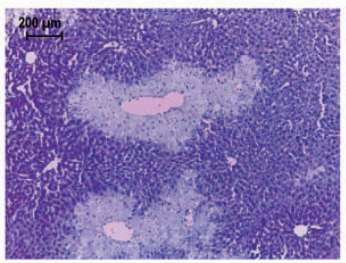

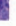

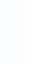


toxicity in germ-free mice by others ${ }^{15}$ further confirm the crucial role of PAMPs secreted by gut microbiota in APAP-mediated liver failure. Together, these results indicate synergy between TLR signaling by PAMPs and sterile inflammation mediated by DAMPs in APAP-LPS-induced toxicity/mortality in mice and the ability of Chtx in blocking the liver toxicity. The current drug of choice NAC for clinical management of APAP-induced liver toxicity was not found to block mortality in the toxicity model system used in the present study (Figure 1c) although NAC was reported several years ago to be decreasing inflammation in experimental animals ${ }^{21}$ based on which clinical trials were undertaken and found to be useful. ${ }^{22}$ The results of present study indicate that Chtx is far superior to NAC in mitigating in vivo toxicity mediated by APAP.

Intracellular signaling from HMGB1-RAGE, ATP-P2X7 and/or mitochondrial DNA-TLR9 interactions post tissue damage has been reported to activate NLRP3 inflammasome complex, leading to the production of active IL-1 $\beta$ and IL-18 by proteolytic cleavage mediated by cleaved caspase-1. ${ }^{13,33,34}$ Thus, activation of inflammasome complex and proteolytic cleavage of pro-caspase- 1 is a critical event in maintaining the inflammatory cascade, as it forms a bridge between TLR signaling and sterile inflammation. Our demonstration of NRLP activation by co-administration of non-lethal dose of APAP and low dose of LPS (either of them in isolation was insufficient to mediate toxcity/mortality) further validates our interpretation on synergy between TLR4-mediated signaling and sterile inflammation. In addition, significantly diminished activation of inflammasome by Chtx in mice challenged with lethal APAP dose further confirms the critical role of inflammasome activation in APAP-induced acute liver failure and it also indicates that blockade of this pathway can lead to protection against APAP-induced mortality.

In conclusion, the present study offers a vital model of APAP-induced hepatotoxicity in synergy with PAMPs such as LPS and reveals critical role of LPS and gut microbiota in APAP-induced liver failure. It further demonstrates that Chtx, which inhibits LPS-mediated endotoxemia by competitive binding through TLR4, protects mice against APAP-induced inflammation and mortality. Thus, Chtx being a nonimmunogenic small molecular weight carbohydrate with the ability to block TLR4-mediated inflammation and to activate anti-inflammatory alternate pathway of macrophages appears to be a promising molecule for clinical management of APAP toxicity and appropriate clinical trials could lead to its use in intensive care medicine units.

\footnotetext{
Materials and Methods

Reagents. APAP, LPS from Escherichia coli serotype 055:B5 and NAC were purchased from Sigma-Aldrich (St. Louis, MO, USA). Hexa-N-acetyle Chtx was from Dextra Laboratories Ltd. (West Berkshire, UK). Bio-Plex Pro Mouse Cytokine 23-plex Assay kit was from Bio-Rad (Hercules, CA, USA). cDNA Synthesis Kit and Q-PCR SYBR mix were from Agilent Technologies (Santa Clara, CA, USA). Arginase activity assay kit was from Sigma-Aldrich (St. Louis, MO, USA). Colorimetric TUNEL assay kit was from Promega (Madison, WI, USA). Anti-mouse antibodies to CD14-(PE) and Ly6G-(perCP-Cy5.5) were from eBiosciences (San Diego, CA, USA) and BD Biosciences (New Jersey, NJ, USA) respectively. Antibodies to caspase-1 and actin were from Santacruz Biotechnology (Dallas, TX, USA) and Sigma-Aldrich, respectively.
}

Table 1 Primers used in the study

\begin{tabular}{ll}
\hline Primer name & Sequence \\
\hline IL-1 $\beta$ & F-5'-TGCCACCTTTTGAGAGTGATG-3' \\
RN-5'-AAGGTCCACGGGAAAGACAC-3' & F-5'-AGGCACTCCCCCAAAAGAG-3' \\
& R-5'-TTTGCTACGACGTGGGCTAC-3' \\
Arginase-1 & F-5'-TTTTAGGGTTACGGCCGGTG-3' \\
TLR2 & R-5'-CCTCGAGGCTGTCCTTTTGA-3' \\
& R-5'-CATTGTTCCCTGTGTTGCTG-3' \\
TLR4 & F-5'-AATCCCTGCATAGAGGTAGTT-3' \\
& R-5'-GGTGGTGTAAGCCATGCCA-3' \\
$\beta$-Actin & F-5'-CTAGGCACCAGGGTGTGATG-3' \\
& R-5'-TGGCCTTAGGGTTCAGGGG-3' \\
\hline
\end{tabular}

Animals. C57BL/6 mice were obtained from National Institute of Immunology, New Delhi, India, originally from Jackson Laboratories (Bar Harbor, Maine, USA). Breeding and maintenance were carried out at Institute of Life Sciences, Bhubaneswar, India. Male mice (8-10 weeks old) were used throughout the investigation. Experimental protocol was approved by Institutional Animal Ethics Committee (IAEC) for conducting experiments using mice and approved protocols were strictly followed. The study was carried out in strict accordance with the recommendations of the Committee for Prevention of Cruelty and Safety of Experiments with Animals (CPCSEA) that supervises care and use of laboratory experimentation through their nominees in the Institutional animal ethics committee.

APAP-induced hepatotoxicity. APAP solution was prepared in sterile DPBS at $20 \mathrm{mg} / \mathrm{ml}$, heated at $55^{\circ} \mathrm{C}$ with agitation and used freshly. Mice were starved for $18 \mathrm{~h}$ and injected intraperitoneally (i.p.) with APAP at 200, 350 and/or $400 \mathrm{mg} / \mathrm{kg}$ body weight (b.w.). Mice were killed by $\mathrm{CO}_{2}$ inhalation at 12 or $24 \mathrm{~h}$ post APAP injection for sampling or observed till day 5 for mortality.

Antibiotic treatment. C57BL/6 mice were gavage-fed with antibiotic cocktail containing vancomycin $(50 \mathrm{mg} / \mathrm{kg} \mathrm{b.w.),} \mathrm{neomycin} \mathrm{(100} \mathrm{mg/kg} \mathrm{b.w.),} \mathrm{metronidazole}$ (100 mg/kg b.w.), ampicillin (100 kg/kg b.w.) and amphotericin B (1 mg/kg b.w.) twice daily over a period of 21 days along with ampicillin $(1 \mathrm{mg} / \mathrm{ml})$ in drinking water ad libitum to generate gut microbiota-depleted mice. Microbiota estimate revealed about $97 \%$ reduction of cultivable bacteria (CFU) in stool of antibiotic-treated mice in comparison with untreated control mice.

Chtx, NAC and LPS treatment. Solutions of Chtx, NAC and LPS were prepared in sterile DPBS and stored at $-20^{\circ} \mathrm{C}$. Chtx was administered i.p. at $10 \mathrm{mg} / \mathrm{kg}$ b.w. as our earlier finding showed inhibition of LPS-induced inflammation by Chtx at a dose of $250 \mu \mathrm{g}$ per mouse (i.e., $10 \mathrm{mg} / \mathrm{kg}$ b.w. for a mouse of $25 \mathrm{~g}$, which is the average body weight of healthy adult mouse). ${ }^{26}$ Treatment was given simultaneously or $6 \mathrm{~h}$ post APAP challenge once or at 6 and $18 \mathrm{~h}$ post APAP challenge twice. NAC was dosed at $300 \mathrm{mg} / \mathrm{kg}$ b.w. as it has been used as a standard dose in literature. ${ }^{7}$ Administration was performed i.p. once at 1.5 or $6 \mathrm{~h}$ post APAP or twice at 6 and $18 \mathrm{~h}$ post APAP. A single i.p. dose of LPS (10 mg/kg b.w.) given simultaneously with APAP (200 mg/kg b.w) was used for the second model of APAP toxicity used in this study.

Sample collection and processing. Blood collected in ACD anticoagulant $(15 \% \mathrm{v} / \mathrm{v})$ by cardiac puncture after euthanasia were aliquoted for analysis by flow cytometry and the rest centrifuged at 3000 r.p.m. for $10 \mathrm{~min}$ for plasma collection. Three milliliters of chilled DPBS were injected in the peritoneum, left for $5 \mathrm{~min}$ and aspirated to collect peritoneal exudates. Cells were pelleted at $400 \times g$ for 5 min and used immediately for flow cytometry analysis. Cell-free peritoneal lavage and plasma samples were stored at $-80^{\circ} \mathrm{C}$ for cytokine assay. Liver tissues were collected in Trizol, RIPA buffer or 10\% formalin for RNA isolation, protein extraction or histology, respectively.

Measurement of liver enzymes and arginase activity. Plasma levels of aspartate amino transferase and alanine amino transferase were measured using clinical chemistry analyzer (ERBA Chem-5X, Transasia, Mumbai, India). Arginase activity in liver tissue extracts was measured using Arginase activity assay kit following the manufacturer's instructions (Sigma-Aldrich, St. Louis, MO, USA). 
Histopathology. Formalin-fixed liver tissues were embedded in paraffin and cut into $5-\mu \mathrm{m}$ thick sections. Replicate sections were stained either with H\&E or TUNEL for microscopic assessment of centrilobular necrosis and DNA fragmentation, respectively. Area of necrosis was scored for whole tissue sections and the numbers of TUNEL-positive cells were counted in 10 high-power fields ( $\times 400$ magnification) using ImageJ software.

Q-polymerase chain reaction. Total RNA was isolated from liver samples using Trizol (Life Technologies, Santa Clara, CA, USA) and first strand CDNA was prepared using a kit following the manufacturer's instructions. Real-time Q-PCR was performed, $c$ T values were normalized with $\beta$-actin and results were expressed as fold change with respect to PBS control. Primers used in the study are shown in Table 1.

Cytokine assay. Cytokine levels in plasma and peritoneal exudates were measured using Bio-plex Pro Assays-23-plex following the manufacturer's instruction and data were acquired in Bio-Plex 200 system (Bio-Rad).

Flow cytometry analysis. Whole blood $(50 \mu l)$ and peritoneal lavage cells were stained with anti-mouse antibodies to CD14-(PE) and Ly6G-(perCP-Cy5.5) following a standard protocol. Stained cells were acquired and analyzed in BD LSRFortessa, using BD FACS Diva software (version 7.0).

Western blot analysis. Protein was extracted from liver tissues using RIPA buffer and western blot analysis for caspase-1 was performed according to standard protocols. Densitometric analysis of protein bands was performed using ImageJ software. Actin was used as sample loading control.

Statistics. Kaplan-Meier plots and statistical analysis were performed using GraphPad Prism software (version 5.01) and results were expressed as mean \pm S.E.M. Groups were compared by two-tailed non-parametric $t$-test and $P$ values less than 0.05 were considered as significant (at $95 \%$ confidence intervals).

\section{Conflict of Interest}

The authors declare no conflict of interest.

Acknowledgements. The Institute of Life Sciences is fully funded by Department of Biotechnology, Government of India. The work was conducted with intramural core grants to Institute of Life Sciences, Bhubaneswar from Department of Biotechnology, Government of India. PKB was supported with a Senior Research Fellowship from Council of Scientific and Industrial Research, New Delhi.

\section{Author contributions}

PKB performed most of the experimental work, analyzed data and wrote the first draft of the manuscript; RM and BKP performed some of the experimental work; SS performed histology of liver samples and scoring of necrosis; SS contributed in interpretation of results; BR designed the project, interpreted the results and finalized the manuscript.

1. Ichai P, Samuel D. Epidemiology of liver failure. Clin Res Hepatol Gastroenterol 2011; 35 : 610-617.

2. Larson AM, Polson J, Fontana RJ, Davern TJ, Lalani E, Hynan LS et al. Acetaminopheninduced acute liver failure: results of a United States multicenter, prospective study. Hepatology 2005; 42: 1364-1372.

3. Lee WM. Acetaminophen toxicity: changing perceptions on a social/medical issue. Hepatology 2007; 46: 966-970.

4. Davidson DG, Eastham WN. Acute liver necrosis following overdose of paracetamol. Br Med J 1966; 2: 497-499.

5. Dahlin DC, Miwa GT, Lu AY, Nelson SD. N-acetyl-p-benzoquinone imine: a cytochrome P-450-mediated oxidation product of acetaminophen. Proc Natl Acad Sci USA 1984; 81: 1327-1331.

6. Mitchell JR, Jollow DJ, Potter WZ, Gillette JR, Brodie BB. Acetaminophen-induced hepatic necrosis. IV. Protective role of glutathione. J Pharmacol Exp Ther 1973; 187: 211-217.

7. Saito C, Zwingmann C, Jaeschke $H$. Novel mechanisms of protection against acetaminophen hepatotoxicity in mice by glutathione and $\mathrm{N}$-acetylcysteine. Hepatology 2009; 51: 246-254.

8. Jollow DJ, Mitchell JR, Potter WZ, Davis DC, Gillette JR, Brodie BB. Acetaminophen-induced hepatic necrosis. II. Role of covalent binding in vivo. J Pharmacol Exp Ther 1973; 187: 195-202.
9. Jaeschke $\mathrm{H}$, Williams $\mathrm{CD}$, Ramachandran $\mathrm{A}$, Bajt ML. Acetaminophen hepatotoxicity and repair: the role of sterile inflammation and innate immunity. Liver Int 2011; 32: 8-20.

10. Hoque R, Sohail MA, Salhanick S, Malik AF, Ghani A, Robson SC et al. P2X7 receptormediated purinergic signaling promotes liver injury in acetaminophen hepatotoxicity in mice. Am J Physiol Gastrointest Liver Physiol 2012; 302: G1171-G1179.

11. Lawson JA, Farhood A, Hopper RD, Bajt ML, Jaeschke $H$. The hepatic inflammatory response after acetaminophen overdose: role of neutrophils. Toxicol Sci 2000; 54 : 509-516.

12. Holt MP, Cheng L, Ju C. Identification and characterization of infiltrating macrophages in acetaminophen-induced liver injury. J Leukoc Biol 2008; 84: 1410-1421.

13. Imaeda AB, Watanabe A, Sohail MA, Mahmood S, Mohamadnejad M, Sutterwala FS et al. Acetaminophen-induced hepatotoxicity in mice is dependent on Tlr9 and the Nalp3 inflammasome. J Clin Invest 2009; 119: 305-314.

14. Shah N, Montes de Oca M, Jover-Cobos M, Tanamoto K, Muroi M, Sugiyama K et al. Role of toll-like receptor 4 in mediating multiorgan dysfunction in mice with acetaminophen induced acute liver failure. Liver Transpl 2013; 19: 751-761.

15. Possamai LA, McPhail MJ, Khamri W, Wu B, Concas D, Harrison M et al. The role of intestinal microbiota in murine models of acetaminophen-induced hepatotoxicity. Liver Int 2014; 35: 764-773.

16. Yohe HC, O'Hara KA, Hunt JA, Kitzmiller TJ, Wood SG, Bement JL et al. Involvement of Tolllike receptor 4 in acetaminophen hepatotoxicity. Am J Physiol Gastrointest Liver Physio 2006; 290: G1269-G1279.

17. Su GL, Gong KQ, Fan MH, Kelley WM, Hsieh J, Sun JM et al. Lipopolysaccharide-binding protein modulates acetaminophen-induced liver injury in mice. Hepatology 2005; 41 : 187-195.

18. Salama M, Elgamal M, Abdelaziz A, Ellithy M, Magdy D, Ali L et al. Toll-like receptor 4 blocker as potential therapy for acetaminophen-induced organ failure in mice. Exp Ther Med 2015; 10: $241-246$.

19. Su GL, Hoesel LM, Bayliss J, Hemmila MR, Wang SC. Lipopolysaccharide binding protein inhibitory peptide protects against acetaminophen-induced hepatotoxicity. Am J Physiol Gastrointest Liver Physiol 2010; 299: G1319-G1325.

20. Lauterburg BH, Corcoran GB, Mitchell JR. Mechanism of action of $\mathrm{N}$-acetylcysteine in the protection against the hepatotoxicity of acetaminophen in rats in vivo. J Clin Invest 1983; 71 : 980-991.

21. Piperno E, Berssenbruegge DA. Reversal of experimental paracetamol toxicosis with $\mathrm{N}$-acetylcysteine. Lancet 1976; 2: 738-739.

22. Prescott LF, Illingworth RN, Critchley JA, Stewart MJ, Adam RD, Proudfoot AT. Intravenous $\mathrm{N}$-acetylcystine: the treatment of choice for paracetamol poisoning. Br Med J 1979; 2 : 1097-1100.

23. Yang R, Miki K, He X, Killeen ME, Fink MP. Prolonged treatment with $\mathrm{N}$-acetylcystine delays liver recovery from acetaminophen hepatotoxicity. Crit Care 2009; 13: R55.

24. Whyte IM, Francis B, Dawson AH. Safety and efficacy of intravenous $\mathrm{N}$-acetylcysteine for acetaminophen overdose: analysis of the Hunter Area Toxicology Service (HATS) database. Curr Med Res Opin 2007; 23: 2359-2368.

25. James LP, McCullough SS, Lamps LW, Hinson JA. Effect of $\mathrm{N}$-acetylcysteine on acetaminophen toxicity in mice: relationship to reactive nitrogen and cytokine formation. Toxicol Sci 2003; 75: 458-467.

26. Panda SK, Kumar S, Tupperwar NC, Vaidya T, George A, Rath S et al. Chitohexaose activates macrophages by alternate pathway through TLR4 and blocks endotoxemia. PLOS Pathog 2012; 8: e1002717.

27. Gardner CR, Hankey P, Mishin V, Francis M, Yu S, Laskin JD et al. Regulation of alternative macrophage activation in the liver following acetaminophen intoxication by stem cell-derived tyrosine kinase. Toxicol Appl Pharmacol 2012; 262: 139-148.

28. Bailey WJ, Holder D, Patel H, Devlin P, Gonzalez RJ, Hamilton V et al. A performance evaluation of three drug-induced liver injury biomarkers in the rat: alpha-glutathione S-transferase, arginase 1, and 4-hydroxyphenyl-pyruvate dioxygenase. Toxicol Sci 2012; 130: 229-244.

29. Ashamiss F, Wierzbicki Z, Chrzanowska A, Scibior D, Pacholczyk M, Kosieradzki M et al. Clinical significance of arginase after liver transplantation. Ann Transplant 2004; 9 . $58-60$

30. Nishio N, Okawa Y, Sakurai H, Isobe K. Neutrophil depletion delays wound repair in aged mice. Age (Dordr) 2008; 30: 11-19.

31. Kolaczkowska E, Kubes P. Neutrophil recruitment and function in health and inflammation Nat Rev Immunol 2013; 13: 159-175.

32. Mariathasan S, Monack DM. Inflammasome adaptors and sensors: intracellular regulators of infection and inflammation. Nat Rev Immunol 2007; 7: 31-40.

33. Tschopp J, Schroder K. NLRP3 inflammasome activation: the convergence of multiple signalling pathways on ROS production? Nat Rev Immunol 2010; 10: 210-215.

34. Cai C, Huang H, Whelan S, Liu L, Kautza B, Luciano J et al. Benzyl alcohol attenuates acetaminophen-induced acute liver injury in a Toll-like receptor-4-dependent pattern in mice. Hepatology 2014; 60: 990-1002.

35. Maddox JF, Amuzie CJ, Li M, Newport SW, Sparkenbaugh E, Cuff CF et al. Bacterial- and viral-induced inflammation increases sensitivity to acetaminophen hepatotoxicity. J Toxicol Environ Health A 2009; 73: 58-73.

36. Roth RA, Harkema JR, Pestka JP, Ganey PE. Is exposure to bacterial endotoxin a determinant of susceptibility to intoxication from xenobiotic agents? Toxicol Appl Pharmacol 1997; 147: 300-311. 
37. Lind RC, Gandolfi AJ, Sipes IG, Brown BR Jr. The involvement of endotoxin in halothaneassociated liver injury. Anesthesiology 1984; 61: 544-550.

38. Shaw PJ, Hopfensperger MJ, Ganey PE, Roth RA. Lipopolysaccharide and trovafloxacin coexposure in mice causes idiosyncrasy-like liver injury dependent on tumor necrosis factoralpha. Toxicol Sci 2007; 100: 259-266.

39. Watkins PB, Kaplowitz N, Slattery JT, Colonese CR, Colucci SV, Stewart PW et al. Aminotransferase elevations in healthy adults receiving 4 grams of acetaminophen daily: a randomized controlled trial. JAMA 2006; 296: 87-93.

40. Liu J, Sendelbach LE, Parkinson A, Klaassen CD. Endotoxin pretreatment protects against the hepatotoxicity of acetaminophen and carbon tetrachloride: role of cytochrome P450 suppression. Toxicology 2000; 147: 167-176.

41. Saiman Y, Friedman SL. The role of chemokines in acute liver injury. Front Physiol 2012 3: 213.

42. Marra F, Tacke F. Roles for chemokines in liver disease. Gastroenterology 2014; 147 577-594 e571.

43. Martins AJ, Spanton S, Sheikh HI, Kim SO. The anti-inflammatory role of granulocyte colonystimulating factor in macrophage-dendritic cell crosstalk after Lactobacillus rhamnosus GR-1 exposure. J Leukoc Biol 2011; 89: 907-915.
44. Gorgen I, Hartung T, Leist M, Niehorster M, Tiegs G, Uhlig S et al. Granulocyte colony-stimulating factor treatment protects rodents against lipopolysaccharide-induced toxicity via suppression of systemic tumor necrosis factor-alpha. J Immunol 1992; 149: 918-924.

cc) (i) Cell Death and Disease is an open-access journal published by Nature Publishing Group. This work is licensed under a Creative Commons Attribution 4.0 International License. The images or other third party material in this article are included in the article's Creative Commons license, unless indicated otherwise in the credit line; if the material is not included under the Creative Commons license, users will need to obtain permission from the license holder to reproduce the material. To view a copy of this license, visit http://creativecommons.org/licenses/by/4.0/

Supplementary Information accompanies this paper on Cell Death and Disease website (http://www.nature.com/cddis) 